\title{
Effect of casein and whey proteins on examination stress
}

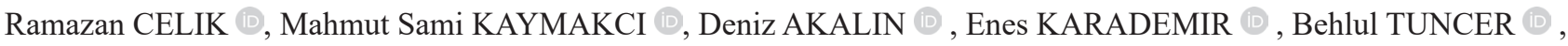 \\ Gokhan BICIM ㄷ, , Ayse Mine YILMAZ ㄹ , A. Suha YALCIN
}

\begin{abstract}
Objective: In this study we aimed to evaluate the effects of casein and whey protein supplementation on examination stress. We have investigated different parameters of oxidative stress and immune function.

Materials and Methods: The participants were divided into three groups: control, casein and whey. Casein and whey groups were supplemented with either casein or whey protein for 15 days. Blood samples were obtained at the beginning of the study (Day 0), on the examination day (Day 16) and five days after the examination (Day 21). Antioxidant capacity, glutathione, cortisol and cytokine levels (TNF-a, IL-6, IL-12) were measured.

Results: An increase in antioxidant capacity and glutathione levels of the participants using whey protein was observed. Whey protein supplementation did not affect cortisol levels, but participants taking whey protein showed an increase in serum TNF-a and IL-6 levels.

Conclusion: It is suggested that the use of whey protein strengthens the response to oxidative stress by increasing antioxidant capacity and glutathione levels, while supporting the immune system via cytokine release.
\end{abstract}

Keywords: Whey protein, Antioxidant capacity, Glutathione, Cortisol, Cytokine

This work was presented at Marmara University School of Medicine Students' Congress-2018 (MASCO-2018), Istanbul and at the European Cooperation in Science and Technology (COST) Action CA16112NutRedOx Meeting.

Ramazan Celik, Mahmut Sami Kaymakci, Deniz Akalin, Enes Karademir, Behlul Tuncer

Medical Student, School of Medicine, Marmara University, Başıüyük, Maltepe, Istanbul, Turkey

Gokhan Bicim, Ayse Mine Yilmaz, A.Suha Yalcin (西)

Department of Biochemistry, School of Medicine, Marmara University, Başıüyük, Maltepe, Istanbul, Turkey

e-mail:asyalcin@marmara.edu.tr

\section{Introduction}

Milk consists of approximately $87 \%$ water, 5\% sugar (mainly lactose), $3.5 \%$ proteins and $1 \%$ salt. Among the milk proteins, caseins represent $80 \%$ and remaining $20 \%$ is the soluble proteins. Whey is the remaining liquid, which contains the soluble proteins after precipitation of casein during cheese production. Whey proteins have many beneficial effects on human health [1,2]. Among these are antioxidative, anti-hypertensive, anti-carcinogenic, hypocholesterolemic and opioidergic effects in addition to their immune-regulatory roles.

Oxidative stress is a condition resulting from the imbalance between the amount of endogenous and/ or exogenous reactive oxygen species (ROS) and the antioxidant defense system [3]. The most important component of the antioxidant defense system is glutathione (GSH), which functions either by directly scavenging free radicals or by participating in enzymatic degradation of ROS [4]. GSH plays an important role in cell signaling through its influence on the intracellular redox status and recent evidence suggests that it can also modulate the immune response. The inability of the cell to import GSH intact has prevented its supplementation. The rate-limiting step in GSH synthesis is dependent on intracellular availability of cysteine [5]. Use of a whey based protein supplement that is rich in cysteine, increases GSH concentrations of circulating lymphocyte and plasma [6,7].

On the other hand, stress and exercise can negatively influence immune function through a variety of mechanisms. Firstly, blood glucose levels are lowered and this increases the levels of stress hormones such as cortisol that affect immune function. Exercise also leads to generation of ROS and oxidative stress, which may lead to apoptosis of susceptible 
immune cells [8]. Physiological and psychological stresses are found to activate the sympathetic nervous system and increase the activity of the hypothalamic-pituitary-adrenal axis leading to increased levels of catecholamines and glucocorticoids [9]. Additionally, acute stress and chronic stress are both associated with increased production and/ or release of pro-inflammatory cytokines and decreases in anti-inflammatory cytokines [10]. In this study, we aimed to evaluate the effects of casein and whey protein supplementation on examination stress by determining different parameters of oxidative stress (plasma antioxidant capacity and erythrocyte glutathione levels) and immune function (plasma TNF- $\alpha$, IL-6 and IL-12 levels).

\section{Materials and Methods}

The study was approved by the institutional ethics committee (8.12.2017 - 09.2017.720) and comprised 36 participants who were third grade medical students at Marmara University School of Medicine. Informed consent was obtained from all participants who were randomly divided into three groups: control, casein and whey protein. The control group did not receive any nutritional supplementation, while the other two groups were supplemented with either casein (33 g) or whey protein $(44 \mathrm{~g})$, once daily for 15 days in addition to their normal diets. Casein and whey proteins were obtained from Kavi Gida, Istanbul, Turkey in powder form and were prepared as suggested by the manufacturer. Blood samples were obtained after an overnight fasting period at the beginning of the study (Day 0), on the examination day (Day 16) and post-examination (Day 21). Blood was centrifuged to separate plasma and erythrocyte. Plasma and erythrocyte lysates were stored at $-20^{\circ} \mathrm{C}$ until use.

\section{Biochemical determinations}

Cupric ion reducing antioxidant capacity (CUPRAC) in plasma was determined as described by Apak et al. [11]. The chromogenic oxidizing reagent used for the assay was bis(neocuproine)copper(II) cation acting as an outersphere electron-transfer agent. The chromophore was formed by reduction of this reagent with antioxidants. The reaction was essentially complete within 30 minutes and the absorbance of the $\mathrm{Cu}(\mathrm{I})$-chelate formed was measured at $450 \mathrm{~nm}$. GSH concentration of the erythrocyte lysates was assayed by the Ellman method using 5,5'-dithiobis2-nitrobenzoic acid (DTNB) [12]. The method was based on the development of a yellow color when DTNB is added to sulfhydryl compounds. The color that developed was fairly stable for about 10 minutes and the absorbance was read at $412 \mathrm{~nm}$. Plasma TNF- $\alpha$, IL-6 and IL-12 levels were determined using commercial ELISA kits (Thermo Scientific Inc., USA). Cortisol measurements were made by an immunoassay analyzer (Beckman Coulter Inc., USA).

\section{Statistical Analysis}

Data were analyzed by using one-way analysis of variance (ANOVA). Differences between groups were determined with Tukey's multiple comparison test. Significance of differences was taken at the level of $\mathrm{p}<0.05$. Calculations were done using Prism 6.0 (GraphPad Software, San Diego, CA, USA).

\section{Results}

The study was carried out with 36 students who accepted to participate voluntarily, 25 of the participants (69.4\%) were male. There was no significant difference between the three groups in terms of their age, body mass index, nutrition, physical activity and tobacco or alcohol use. Figure 1 shows the changes in plasma antioxidant capacity and erythrocyte glutathione levels of the three groups. There was no significant difference between the antioxidant capacity values of the three groups. However, although not statistically significant, the values of the control group suggested that examination stress might have a diminishing effect on antioxidant capacity. When the antioxidant capacity values were compared on a daily basis, there was no difference on Day 0 values but the values of whey group were slightly higher than control and casein groups on Day 16 and Day 21. There was no significant difference between glutathione values on Day 0 and Day 16. However, on Day 21 glutathione levels of the whey group were significantly $(p<0.05)$ higher than the other two groups. There was no significant difference between plasma cortisol levels of the three groups at different times (data not shown). Table I shows plasma cytokine levels of all three groups on the examination day. Cytokine levels were all significantly high when compared to initial values. The percentage increase in TNF-a, IL-6 and IL-12 values were 11.9-33.9\%; 23.8$57.7 \%$ and $12.6-77.7 \%$, respectively. TNF-a and IL-12 values of the whey group were significantly higher than the control group on the examination day. 

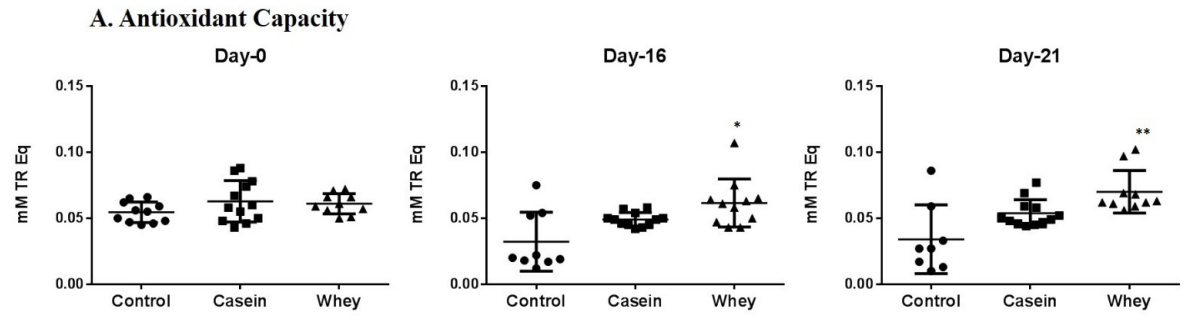

B. Glutathione
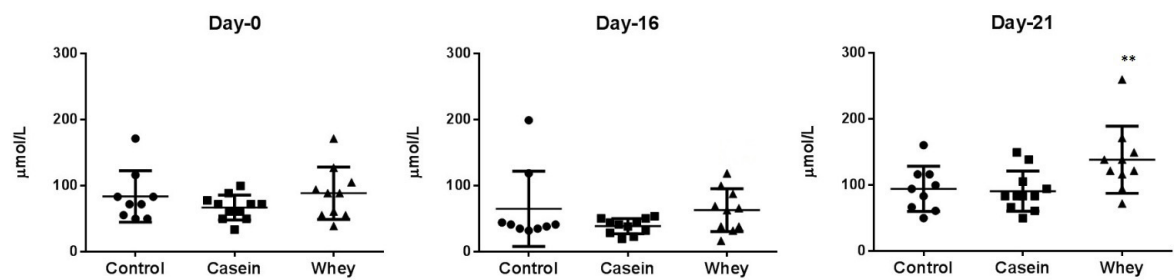

Figure 1.Changes in plasma antioxidant capacity and erythrocyte glutathione levels of control, casein and whey groups at the beginning of the study (Day 0), on the examination day (Day 16) and post-examination (Day 21).

* Significantly higher $(\mathrm{p}<0.05)$ compared to Day 0 values

** Significantly higher $(\mathrm{p}<0.01)$ compared to Day 0 values

Table I. Plasma cytokine levels of the control, casein and whey groups on the examination day

\begin{tabular}{|l|l|l|l|}
\hline & $\begin{array}{l}\text { TNF-a } \\
(\mathbf{p g} / \mathbf{d l})\end{array}$ & $\begin{array}{l}\text { IL-6 } \\
(\mathbf{p g} / \mathbf{d l})\end{array}$ & $\begin{array}{l}\text { IL-12 } \\
(\mathbf{p g} / \mathbf{d l})\end{array}$ \\
\hline Control & $381.2 \pm 89.7$ & $28.3 \pm 11.2$ & $42.6 \pm 26.5$ \\
\hline Casein & $372.7 \pm 5.79$ & $22.3 \pm 10.5$ & $54.06 \pm 57.4$ \\
\hline Whey & $456.4 \pm 90.5^{*}$ & $28.4 \pm 15.1$ & $67.2 \pm 45.02^{*}$ \\
\hline
\end{tabular}

* Significantly higher $(\mathrm{p}<0.01)$ compared to controls

\section{Discussion}

Whey protein is frequently used to enhance antioxidant defenses [13]. The antioxidant activity exhibited by whey protein occurs because of its iron-chelating properties but perhaps more importantly through provision of the amino acids required for GSH synthesis [14]. Whey proteins contain high amounts of cysteine and methionine, and also contributes glutamine which can be converted to glutamate: all are amino acids required for GSH synthesis. When levels of cysteine are low, it is preferentially used for protein synthesis and hence provision of cysteine through whey proteins is important to enhance GSH biosynthesis. Glutathione has strong antioxidant properties and is a scavenger of ROS. This is achieved through several mechanisms; firstly, GSH peroxidase catalyzes reduction of hydrogen peroxide and organic peroxides; secondly, GSH is able to scavenge hydroxyl radicals and singlet oxygen; and finally, GSH is able to directly or indirectly reduce tocopherol radicals thereby preventing free radical chain reaction and lipid peroxidation [4]. A study carried out in young and healthy athletes showed that daily consumption of $20 \mathrm{~g}$ of whey protein for 12 weeks enhanced GSH levels, improved athletic performance, and decreased body fat [15]. Whey protein has been shown to increase total antioxidant capacity and GSH levels in resistance-trained subjects [16]. Our results were in accordance with these studies and showed that whey protein consumption corrected stress-induced depletion of antioxidant capacity and increased glutathione levels slightly in the post-examination group. Cell-culture studies demonstrated that lowering intracellular GSH levels decreased survival of TNF-a stimulated T-lymphocytes and altered T cell function [7]. Thus, GSH is able to assist the body in combating a number of stress related diseases through its action on the immune system.

On the other hand, medical students must complete an intensive program especially in their first three years. Accordingly, stress is very common among medical students during the course of their training. Academic examinations represent one type of naturalistic stressor and several studies have indicated that naturalistic stressors upregulate immune functions [17, 18], while other studies have reported that they rather down-regulate immune responses $[19,20]$. As mentioned previously, acute stress and chronic stress are both associated with increased production and/ or release of pro-inflammatory cytokines and decreases in 
anti-inflammatory cytokines [10]. Although, we were not able to observe any changes in cortisol, TNF-a and IL-12 levels, values of the whey group were significantly higher than the control group on the examination day.

The mechanisms of stress-related immune alterations have not been fully elucidated. However, cell-mediated immune responses as well as antibody production and release of certain cytokines were reported as being suppressed during times of high stress. The values obtained for our control group suggested that examination stress might have a diminishing effect on antioxidant capacity. There was no significant difference between glutathione levels of different groups but cytokines were all significantly high when compared to initial values. The main drawback of our study was the number of students involved as well as the short duration of the study. Nevertheless, although our results need to be verified by further studies with larger groups that are recruited for longer times, we still believe that consumption of whey proteins will support the immune system by increasing glutathione synthesis.

\section{References}

1. Marshall K. Therapeutic applications of whey proteins. Altern Med Rev 2004; 9:136-56.

2. Yalçın AS. Emerging therapeutic potential of whey proteins and peptides. Curr Pharm Des 2006; 12:1637 - 43. doi: 10.2174/138.161.206776843296

3. Sies H. Oxidative stress: a concept in redox biology and medicine. Redox Biol 2015; 4:180-3. doi: 10.1016/j. redox.2015.01.002

4. Meister A. Glutathione metabolism. Meth Enzymol 1995; 251:3-7. doi: 10.1016/0076-6879(95)51106-7

5. Morcillo EJ, Estrela J, Cortijo J. Oxidative stress and pulmonary inflammation: pharmacological intervention with antioxidants. Pharmacol Res 1999; 40:393-404. doi: 10.3168/jds.S0022-0302(98)75613-9

6. Grey V, Mohammed SR, Smountas AA, Bahlool R, Lands LC. Improved glutathione status in young adult patients with cystic fibrosis supplemented with whey protein. J Cyst Fibrosis 2003; 2:195-8. doi: 10.1016/S1569-1993(03)00097-3

7. Micke P, Beeh KM, Schlaak JF, Buhl R. Oral supplementation with whey proteins increases plasma glutathione levels of HIV-infected patients. Eur J Clin Invest 2001; 31:171-8. doi: 10.1046/j.1365-2362.2001.00781.x
8. Ali A, Lee SJ, Rutherfurd-Markwick KJ. Sports and exercise supplements. In: Deeth HC, Bansal N, eds. Whey Protein from Milk to Medicine. London: Elsevier, 2019: 579, 635. doi: 10.1016/B978-0-12-812124-5.00017-5

9. Assaf AM, Abbassi RA, Al-Binni M. Academic stressinduced changes in Th1 - and Th2-cytokine response. Saudi Pharm J 2017; 25:1237-47. doi: 10.1016/j.jsps.2017.09.009

10. Goebel MU, Mills PJ, Irwin MR, Ziegler MG. Interleukin-6 and tumor necrosis factor-[alpha] production after acute psychological stress, exercise, and infused isoproterenol: differential effects and pathways. Psychosom Med 2000; 62:591-8.

11. Apak R, Güçlü K, Özyürek M, Bektaşoğlu B, Bener M. Cupric ion reducing antioxidant capacity assay for antioxidants in human serum and for hydroxyl radical scavengers. Meth Mol Biol 2010; 594:215-39. doi: 10.1007/978-1-60761-411-1_15

12. Laton M, Roper D. Investigation of the hereditary haemolytic anaemias: Membrane and enzyme abnormalities In: Bain BJ, Bates I, Laffan MA, eds. Dacie and Levis Practical Haematology. London: Elsevier, 2017: 228, 253. doi: 10.1016/B978-0-7020-6696-2.00012-6

13. Kerasioti E, Kiskini A, Veskoukis A, et al. Effect of a special carbohydrate protein cake on oxidative stress markers after exhaustive cycling in humans. Food Chem Toxicol 2012; 50:2805-10. doi: 10.1016/j.fct.2012.04.015

14. Kerasioti E, Stagos D, Priftis A, et al. Antioxidant effects of whey protein on muscle C2C12 cells. Food Chem 2014; 155:271-8. doi:10.1016/j.foodchem.2014.01.066

15. Lands LC, Grey VL, Smountas AA. Effect of supplementation with a cysteine donor on muscular performance. J Appl Physiol 1999; 87:1381-5. doi:10.1152/jappl.1999.87.4.1381

16. Sheikholeslami-Vatani D, Ahmadi-Kani Golzar F. Changes in antioxidant status and cardiovascular risk factors of overweight young men after six weeks supplementation of whey protein isolate and resistance training. Appetite 2012; 59:673-8. doi:10.1016/j.appet.2012.08.005

17. Kang DH, Coe CL, McCarty DO. Academic examinations significantly impact immune responses, but not lung function, in healthy and well-managed asthmatic adolescents. Brain Behav Immun 1996; 10:164-81. doi: 10.1006/brbi.1996.0015

18. Maes M, Song C, Lin A. et al. The effects of psychological stress on humans: increased production of pro-inflammatory cytokines and a Th1-like response in stress-induced anxiety. Cytokine 1998; 10:313-8. doi: 10.1006/cyto.1997.0290

19. Glaser R, Kiecolt-Glaser JK. Stress-induced immune dysfunction: implications for health. Nat Rev Immunol 2005; 5:243-51. doi: 10.1038/nri1571

20. Rojas IG, Padgett DA, Sheridan JF, Marucha PT. Stressinduced susceptibility to bacterial infection during cutaneous wound healing. Brain Behav Immunol 2002; 16:74-84. doi: 10.1006/brbi.2000.0619 